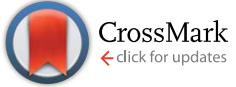

Cite this: RSC Adv., 2015, 5, 24167

Received 16th December 2014 Accepted 23rd February 2015

DOI: $10.1039 / c 4 r a 16485 g$

www.rsc.org/advances

\section{Design of novel tetra-hetero[8]circulenes: a theoretical study of electronic structure and charge transport characteristics $\dagger$}

\begin{abstract}
Vu Thi Thu Huong, Truong Ba Tai* and Minh Tho Nguyen*
In the present work, a series of new tetra-hetero[8]circulenes were theoretically designed in which heteroatoms include $\mathrm{O}, \mathrm{S}, \mathrm{Se}$ and $\mathrm{N}$. Their electronic structure and characteristics of charge transport were investigated using DFT based computational methods. Except for the compounds containing Seatoms ( $3 a$ and $3 b$ ), all remaining compounds exhibit planar and highly symmetrical structures featuring novel aromatic features: the inner eight-membered ring is anti-aromatic and the outer fused rings are aromatic. The predicted UV spectrum and reduction potential of 1 a agree well with available experimental values. Following replacement of $\mathrm{H}$-atoms by $\mathrm{F}$-atoms, the energy levels of the frontier orbitals of $1 b-4 b$ are consistently decreased as compared to those of $1 a-4 a$. Based on the calculated properties of electrochemistry and charge transport, the molecules $1 \mathrm{a}-4 \mathrm{a}$ and $4 \mathrm{~b}$ are suggested to be good candidates for $p$-type semiconductors. More importantly, the molecules $1 b-3 b$ are revealed to be potential ambipolar organic semiconductors.
\end{abstract}

\section{Introduction}

$[n]$ Circulenes, which consist of compounds having two concentric annulene rings, have attracted much attention as an intriguing family of aromatic polycyclic hydrocarbons. Three members of this family, including [5]circulene (corannulene), ${ }^{1}$ [6]circulene (coronene) ${ }^{2}$ and [7] circulene $^{3}$ (pleiadannulene), have experimentally been prepared for a long time and the characteristics of their electronic structure, chemical bonding and adsorption spectra were well determined. Although earlier theoretical studies suggested that [8]circulene is unstable, ${ }^{4}$ this molecule was recently successfully synthesized by $\mathrm{Wu}$ and coworkers. ${ }^{5}$ Their shapes interestingly change from a bowled shape for [5]circulene to a planar structure for [6]circulene and saddled shapes for [7] and [8]circulenes.

Recently, the family of hetero[8]circulenes appears to be even more intriguing. Replacing the outside benzene fused-rings by heterocyclic rings such as furan, thiophene... results in planar heteropolycyclic compounds with highly $\pi$-conjugated electronic structures which can eventually be used in many important applications. Octathio[8]circulene, named as sunflower, $\left(\mathrm{C}_{16} \mathrm{~S}_{8}\right)$ in which all outside fused benzene rings are replaced by eight fused thiophene rings, was for the first time synthesized in $2006,{ }^{6}$ and found as a good p-type organic

Department of Chemistry, University of Leuven, Celestijnenlaan 200F, B-3001 Leuven, Belgium.E-mail:minh.nguyen@chem.kuleuven.be; truong.batai@chem.kuleuven.be $\dagger$ Electronic supplementary information (ESI) available: The xyz-coordinates of the optimized structures $\mathbf{1 a}-\mathbf{4 a}$ and $\mathbf{1 b}-\mathbf{4} \mathbf{b}$ at the neutral state. See DOI: 10.1039/c4ra16485g semiconductor by both experiment and theory. ${ }^{7,8}$ Subsequently, the electronic structure and charge transport properties of its analogues molecules such as $\mathrm{C}_{16} \mathrm{~S}_{4} \mathrm{Se}_{4}$ and $\mathrm{C}_{16} \mathrm{X}_{8}$ with $\mathrm{X}=\mathrm{O}$, Se, $\mathrm{NH}, \mathrm{CH}_{2}, \mathrm{PH}$ and PF were also extensively studied..$^{9-12}$ They were suggested as either p-type or n-type organic semiconducting materials with high rate of charge hopping. More recently, Datta and his co-workers ${ }^{13}$ designed similar molecules, named as Siand Ge-sulflower, in which C-atoms of $\mathrm{C}_{16} \mathrm{~S}_{8}$ were replaced by either Si-atoms or Ge-atoms. These molecules were found to be bowled structures and exhibit a large number of metallic-like states with weak optical absorption. In a recent study, we theoretically designed a series of new hetero[8]circulenes containing borole units. ${ }^{14}$ These heteropolycyclics feature some intriguing aromatic characteristics at both inner and outer rings. Such interesting results stimulated us to further design of new $\pi$-conjugated materials based on the [8]circulene framework.

Tetra-hetero[8]circulenes in which only four fused benzene rings are replaced by four fused hetero-rings, have recently emerged as promising $\pi$-conjugated materials for organic electronic devices. In fact, tetraoxo[8]circulene was already found by experiment since $1960 \mathrm{~s},{ }^{15}$ but its applicable properties were not properly explored. Recently, Minaev and his coworkers performed a series of theoretical and experimental studies on electronic structure, spectroscopic properties, aromaticity and bonding characteristics of tetraoxa[8] circulenes and its derivatives. ${ }^{16,17}$ Pittelkow et al. ${ }^{18}$ reported the preparation of a series of $\pi$-extended tetraoxa[8[circulenes and their optical and electrochemical properties. These compounds showed high thermodynamic stability and can be used as 
promising materials for the development of blue organic lightemitting diodes (OLEDs). More recently, some planar cyclooctatetraenes such as azatrioxa[8]circulenes and diazadioxa[8]circulenes in which one and two O-atoms were replaced by $\mathrm{N}$-atoms were successfully synthesized. Their characteristics of single-crystal X-ray structure, aromaticity, and spectroscopy were investigated in both experiment and theory. ${ }^{19}$ In other way, Minaev et al. ${ }^{\mathbf{2 0 2 1}}$ reported theoretical results on the one- and two-dimensional nano-materials containing tetraoxa[8]circulene monomers. The authors found that these materials can be used as ambipolar organic semiconductors with high mobility for both hole and electron charge carriers.

In order to further explore this intriguing class of heteropolycyclic compounds, we herein performed theoretical studies of structural characteristics, electronic and charge transport properties of tetraoxo[8]circulene 1a and its derivatives in two different series $\mathbf{2 a - 4 a}$ and $\mathbf{1 b}-\mathbf{4 b}$ using DFT-based computational methods. The derivatives are designed by simply replacing oxygen atoms of 1a with sulfur (2a), selenium (3a) and NH-groups (4a). Additionally, replacement of $\mathrm{H}$-atoms of compounds 1a-4a by fluorine results in perfluoronated compounds $\mathbf{1 b}-\mathbf{4 b}$ that are expected to have reduced LUMO energy levels and can thus be used as effective n-type organic semiconductors. Our results show that most of designed molecules exhibit the planar structures with high degree of $\pi$-conjugation and high rate of charge hopping.

\section{Computational methods}

\subsection{Electronic structure calculations}

Optimizations of the relevant geometries and calculations of their harmonic vibrational frequencies are fully performed using DFT. The hybrid functional B3LYP ${ }^{22-24}$ are used in conjunction with the 6-31G(d,p) basis sets. ${ }^{25,26}$ For open-shell systems such as cations and anions, the unrestricted formalism (UB3LYP) is used. This popular functional was proved to be reliable in predicting geometrical parameters and charge transport properties of many $\pi$-conjugated systems. For each species considered, the neutral, anionic and cationic states are characterized. All electronic structure calculations are carried out using the Gaussian 09 (ref. 27) suite of programs.

\subsection{Charge transport properties}

In order to probe the charge transport properties, the hopping model is used. ${ }^{28-33}$ Accordingly, the hole and electron carriers can be jumped between the adjacent molecules of the organic crystals. The rate of charge hopping $(K)$ is estimated by using the Marcus-Hush eqn (1): ${ }^{34}$

$$
K=\left(t^{2} / \hbar\right) \exp \left(-\lambda / 4 k_{\mathrm{B}} T\right) \sqrt{\pi / \lambda k_{\mathrm{B}} T}
$$

where $t$ is the transfer integral between two adjacent molecules, $\lambda$ the reorganization energy, $k_{\mathrm{B}}$ Boltzmann constant and $T$ the temperature ( $298 \mathrm{~K}$ in our calculations). Accordingly, a high rate of charge hopping $K$ is obtained when the transfer integral $(t)$ between two molecules is high, and the monomers have low reorganization energy $(\lambda)$.
The transfer integral is defined by the following expression (2): $:^{35-37}$

$$
t=\left\langle\phi_{i}^{0, \text { site } 1}|F| \phi_{j}^{0, \text { site2 }}\right\rangle
$$

where $\phi_{i}^{0, \text { site } 1}$ and $\phi_{j}^{0, \text { site2 }}$ present the HOMO (or LUMO) of isolated molecules 1 and 2, respectively. $F$ is the Fock operator $(F=$ $S C \varepsilon C^{-1}$ ) of the dimer with a density matrix from non-interacting dimer, where $S$ is the intermolecular overlap matrix, $C$ and $\varepsilon$ are the molecular orbital coefficients and energies, respectively, from one-step diagonalization without iteration.

The transfer integral for hole $\left(t_{\mathrm{h}}\right)$ is calculated as half of the energy difference between the HOMO and HOMO -1 of the dimer, while the transfer integral for electron $\left(t_{\mathrm{e}}\right)$ is half of the energy difference between the LUMO and LUMO +1 of the dimer. These orbital energy levels are obtained using density functional theory (DFT) with the PW91PW91 functional ${ }^{38,39}$ in conjunction with the $6-31 \mathrm{G}(\mathrm{d}, \mathrm{p})$ basis set. This approach has been shown to be suitable and effective in calculations of the transfer integrals of many organic compounds. ${ }^{40-48}$ We should note that the transfer integral is functional dependent property and their values systemically depend on the fraction of nonlocal $\mathrm{HF}$ exchange incorporated in a functional. Sutton et al. ${ }^{\mathbf{4 8 b}}$ showed that the amount of HF exchange substantially affects the transfer integral in a linear fashion with respect to the fraction of nonlocal HF exchange incorporated in a standard hybrid functional.

\subsection{Reduction and oxidization potentials in solution}

The reduction and oxidization potentials of compounds in solution are calculated by using a protocol recently developed by Davis and Fry. ${ }^{49}$ Firstly, optimizations of geometries and calculations of vibrational frequencies of each compound in the neutral, anionic and cationic charge states are performed at the B3LYP/6-31+G(d) level. Their single point electronic energies are obtained using a larger basis set, B3LYP/6-311++G(2df,2p). Addition of a set of diffuse functions in the basis set is necessary to describe the structures of the ions involved in the evaluation. The SMD/IEF-PCM solvation model ${ }^{50}$ in acetonitrile solvent is used to probe the solvent effects. These methods were proven to be effective to obtain the reduction and oxidation potentials of PHA compounds in solution. ${ }^{49,51}$ Davis and Fry ${ }^{49}$ showed that using eqn (4) and (5) results in a mean absolute deviation (MAD) for the polycyclic aromatic hydrocarbons (PAHs) of 0.023 and $0.032 \mathrm{mV}$, respectively.

The absolute potentials at $298 \mathrm{~K}$ are obtained using the following eqn (3):

$$
E_{\mathrm{Abs}}{ }^{298}=E_{\mathrm{calc}^{298}}-0.03766
$$

where $E_{\text {calc }}{ }^{298}$ is calculated from the difference in free energy $(G)$ at $298 \mathrm{~K}$ between the couples neutral/cation and anion/neutral. The value of 0.03766 accounts to small thermal correction for a free electron at $298 \mathrm{~K}^{52}$

The reduction potential is predicted in MeCN solution for the ferrocene-ferrocenium $\left(\mathrm{Fc} / \mathrm{Fc}^{+}\right)$pair, and the standard redox couple are calculated by using the expressions (4) and (5): 


$$
\begin{aligned}
& \text { Reduction: } E_{1 / 2}{ }^{298}=1.056 E_{\mathrm{Abs}}{ }^{298}-4.90 \\
& \text { Oxidation: } E_{1 / 2}{ }^{298}=0.932 E_{\mathrm{Abs}}{ }^{298}-3.94
\end{aligned}
$$

\section{Results and discussion}

\subsection{Electronic structure and aromaticity of compounds}

Geometric optimizations and calculations of harmonic vibrational frequencies of all compounds are performed using the hybrid functional B3LYP in conjugation with the polarized 6-31G(d,p) basic set. This method was demonstrated to provide reliable geometries and charge transport properties of the organic semiconductors in many previous studies. ${ }^{53-58}$ The chemical structures of all compounds are shown in Fig. 1, whereas their shapes are given in the ESI file. $\dagger$

Among the eight compounds considered, $\mathbf{1 a}$ is the only one which has been well described by both experiment and theory. The computed C-O bond length of 1a of $1.385 \AA$ agrees well with the experimental value of $1.392-1.402 \AA^{13}$ The distances between $\mathrm{C}$ and hetero atoms of five-membered rings change somewhat, and in the ordering of $\mathrm{C}-\mathrm{O} \sim \mathrm{C}-\mathrm{N}<\mathrm{C}-\mathrm{S}<\mathrm{C}-\mathrm{Se}$. Consequently, our calculations show that the compounds containing furan (1a and $\mathbf{1 b}$ ), thiophene ( $2 \mathbf{a}$ and $\mathbf{2 b}$ ) and pyrrole ( $\mathbf{4 a}$ and $\mathbf{4 b}$ ) exhibit planar structures whereas the compound containing selenophene (3a and $\mathbf{3 b}$ ) is slightly distorted out of the structural plane due to the large $\mathrm{C}-\mathrm{Se}$ distances. Following attachment of one excess electron into the molecules to form anionic species (or detaching one electron from the molecules to form cationic species), the geometries of the charged species only change somewhat, except for the case of $\mathbf{3 a}$ whose cationic

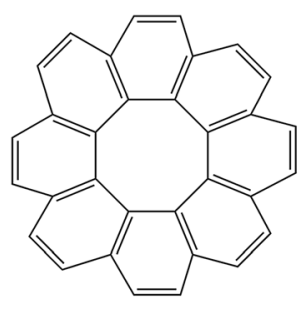

[8]-circulene

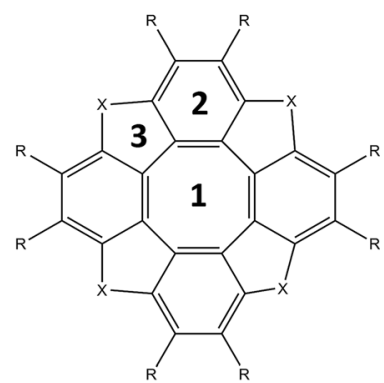

Tetraoxo[8]circulene and its analogues

Fig. 1 Chemical structure of the [8]circulene and hetero[8]circulenes considered.

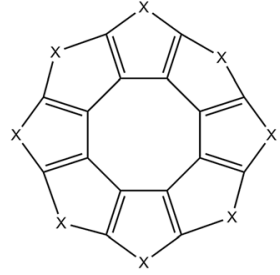

Octathio[8]circulene and its derivatives

$$
\begin{aligned}
& \text { 1a: } X=\mathrm{O} \\
& \text { 2a: } X=\mathrm{S} \\
& \text { 3a: } X=\mathrm{Se} \\
& \text { 4a: } \mathrm{X}=\mathrm{NH}
\end{aligned}
$$

1b: $\mathrm{X}=\mathrm{O}$

2b: $\mathrm{X}=\mathrm{S}$ and $\mathrm{R}=\mathrm{F}$

3b: $\mathrm{X}=\mathrm{Se}$
$\mathbf{4 b}: \mathrm{X}=\mathrm{NH}$ state shows a large distorted shape. Consequently, we can expect that these compounds will have low reorganization energies that can dominate the rate of charge hopping.

Aromaticity is used to describe electron delocalization in compounds. Aromatic compounds usually exhibit high stability, planar and symmetrical structure and good electron delocalization. These are key properties for high charge mobility of $\pi$-conjugated organic molecules. Thus, evaluation of aromaticity of a compound gives us more insight into its electronic properties. Aromatic character is evaluated here using the nuclear independent chemical shift (NICS) index. ${ }^{59,60}$ The NICS $(0)$ values are calculated on ghost atoms located at center of rings 1, 2 and 3 as shown in Fig. 1. It is also known that the NICS(0) values can be affected by distribution of $\sigma$-electrons of compounds. ${ }^{54}$ Thus, the NICS(1) values that are calculated on ghost atoms located at $1 \AA$ distance out of the structural plane can give us more reliable indications.

Computed results in Table 1 showed that the inside eightmembered rings of compounds are anti-aromatic with positive NICS values, whereas all outside rings exhibit aromaticity with negative NICS values. There is negligible difference in aromatic character of molecules with different hetero atoms. In addition, replacing $\mathrm{H}$-atoms of $\mathbf{1 a - 4 a}$ by F-atoms of $\mathbf{1 b}-\mathbf{4 a}$ only change somewhat the aromatic feature of compounds. These aromatic features are similar to those of the sulflower $\mathrm{C}_{18} \mathrm{~S}_{8}$ and its derivatives. ${ }^{45}$ Thus it is expected that these compounds are characterized by high $\pi$-conjugation, and thereby good ability of intramolecular charge transport.

\subsection{Absorption UV spectra of compounds}

The absorption UV spectra of all compounds are predicted using the time-dependent (TD-DFT) method with the B3LYP functional in conjunction with the $6-31+G(d, p)$ basis set. This method was evaluated to give reliable predictions for optical spectra of organic compounds. ${ }^{\mathbf{6 1 , 6 2}}$ The plots of absorption UV spectra of all compounds are displayed in Fig. 2.

There is a good agreement between our theoretical predictions and the available experimental and theoretical results. Accordingly, the UV spectrum of 1a shows two local peaks with

\begin{tabular}{|c|c|c|c|c|c|c|}
\hline \multirow[b]{2}{*}{ Compounds } & \multicolumn{3}{|c|}{$\operatorname{NICS}(0)$} & \multicolumn{3}{|c|}{$\operatorname{NICS}(1)$} \\
\hline & 1 & 2 & 3 & 1 & 2 & 3 \\
\hline $1 \mathrm{a}$ & 8.4 & -10.4 & -9.2 & 5.3 & -10.1 & -9.2 \\
\hline 1b & 7.1 & -13.5 & -12.3 & 4.5 & -10.7 & -8.7 \\
\hline $2 a$ & 6.7 & -9.5 & -10.4 & 3.9 & -9.9 & -8.0 \\
\hline $2 b$ & 6.8 & -12.2 & -10.4 & 4.2 & -10.2 & -7.5 \\
\hline $3 a$ & 4.1 & -10.4 & -15.2 & 7.1 & -8.5 & -13.8 \\
\hline $3 \mathbf{b}$ & 4.3 & -10.0 & -8.1 & 7.0 & -11.7 & -9.1 \\
\hline $4 a$ & 8.0 & -11.0 & -12.0 & 4.1 & -9.6 & -11.1 \\
\hline $4 b$ & 6.7 & -14.3 & -12.5 & 4.9 & -9.9 & -10.7 \\
\hline
\end{tabular}
high intensity centered at 255 and $261 \mathrm{~nm}$ which agree well to the experimental value of $260 \mathrm{~nm} \cdot{ }^{18}$ Another local peak is

Table 1 NICS(0) and NICS(1) values of compounds obtained at B3LYP/ $6-311+G(d)$ 


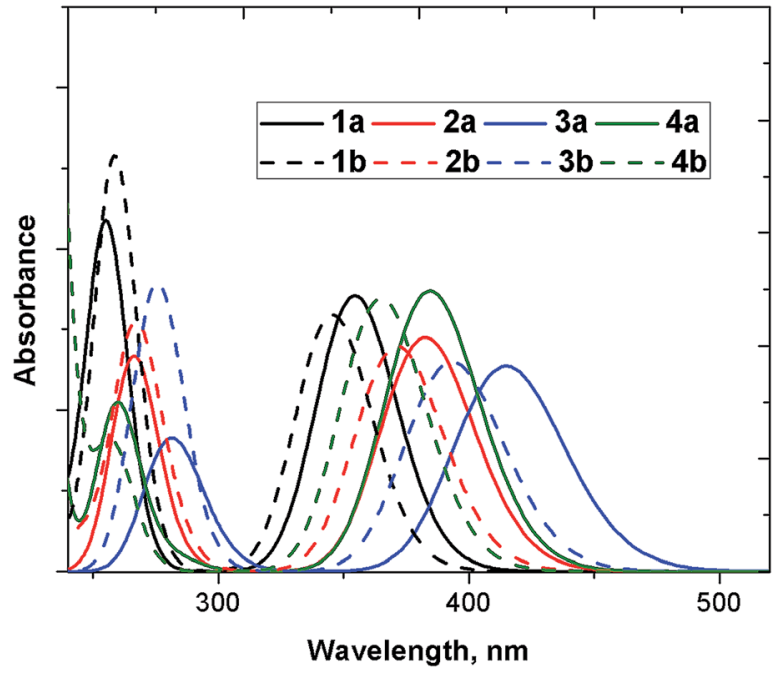

Fig. 2 Plots of the UV spectra of all molecules $1 a-4 a$ and $1 b-4 b$.

located at $354 \mathrm{~nm}$ that is close to the experimental peaks at 358 and $376 \mathrm{~nm} .{ }^{18}$

Our calculations also reveal a local peak at $416 \mathrm{~nm}$ which agrees well with the experimental value of $415 \mathrm{~nm}$. This peak actually corresponds to a $\pi-\pi^{*}$ transition from HOMO to LUMO. However, this absorption has low intensity in both experimental and theoretical spectra. The low absorption intensity corresponds to a small transition moment between the ground and excited states. The transition moment is derived mainly from the integrals of the dipole moment acting on both states. In this case, it is characterized by the small overlap between the transition orbitals HOMO and LUMO. Similar observations were also found for the UV spectra of remaining compounds.

More interestingly, Fig. 2 shows that the UV spectra of compounds considered tend to be red-shifted when O-atoms of $\mathbf{1 a}$ and $\mathbf{1 b}$ are replaced by S- and Se-atoms. Two high intensity peaks at 267 and $383 \mathrm{~nm}$ were found in the UV spectrum of 2a, whereas the $3 \mathbf{a}$ is characterized by two local peaks at 285 and $415 \mathrm{~nm}$. Following perfluorination of compounds 1a-3a, the first local peaks in UV spectra of $\mathbf{1 b} \mathbf{b} \mathbf{3} \mathbf{b}$ is red-shifted, while their second local peaks are blue-shifted as compared to those of 1a-3a, respectively. The UV spectra of $\mathbf{4 a}$ and $\mathbf{4 b}$ are similar to those of $2 \mathbf{a}$ and $\mathbf{2 b}$, respectively.

\subsection{Reduction and oxidation potentials of compounds in the solution}

The values of reduction and oxidation potentials, that are related to the energies of frontier molecular orbitals (FMO), play important role for applicability of organic semiconductors. The energy levels of HOMO (characteristic for p-type semiconductor) and LUMO (for n-type semiconductor) should be close to work functions (WF) in vacuum of electrodes in order to improve their charge transport ability. In experimental studies, some electrodes such as gold (Au) (WF $\sim 5.10 \mathrm{eV}$ ), calcium (WF $2.90 \mathrm{eV}$ ), and magnesium (WF $\sim 3.68 \mathrm{eV}$ ) are commonly used. ${ }^{63}$
While the gold electrode is one of the best electrodes for organic electronic device, the calcium and magnesium electrodes are the preferred ones for $\mathrm{n}$-type organic semiconductors due to the fact that this type of materials usually possesses a LUMO energy level of $\sim 3.0-4.0 \mathrm{eV}$. In this study, the reduction and oxidation potentials and energy levels of frontier orbitals of the molecules examined are calculated using the SMD/IEF-PCM solvation mode $^{64}$ in acetonitrile solvent (see above). All computed values are given in the Table 2, while the shapes of frontier orbitals are displayed in Fig. 3.

The reduction potential of $1 \mathrm{a}$ is equal to $-2.09 \mathrm{eV}$ that is slightly higher than the highest experimental value of $-2.39 \mathrm{eV}$ of $1 \mathrm{a} .{ }^{18}$ It can be observed that the compounds containing group VIA elements 1a-3a and $\mathbf{1 b}-\mathbf{3} \mathbf{b}$ have comparable energy levels of frontier orbitals. The LUMO and HOMO of $\mathbf{4 a}$ and $\mathbf{4} \mathbf{b}$ containing pyrrole units are higher. Additionally, the HOMO energy levels of the 1a-4a vary in a range of $(-5.27)-(-6.27) \mathrm{eV}$, and are in the sequence of $\mathbf{1 a}<\mathbf{2 a}<\mathbf{3 a}<\mathbf{4 a}$. A similar trend is found for the series $\mathbf{1 b} \mathbf{b} \mathbf{- 4} \mathbf{b}$. These values are close to the work function of $5.1 \mathrm{eV}$ of gold electrode, and consequently they are expected to be good candidates for p-type semiconductors.

Replacement of $\mathrm{H}$-atoms in 1a-4a by F-atoms consistently decreases the energy levels of both HOMO and LUMO of $\mathbf{1 b}-\mathbf{4 b}$. More importantly, the LUMOs of $\mathbf{1} \mathbf{b}-\mathbf{3} \mathbf{b}$ have similar energy levels and are equal to $\sim 3.00 \mathrm{eV}$. These values are very close to that of $2.90 \mathrm{eV}$ of the calcium electrode. The LUMO energy levels of 1a-3a are somewhat higher and close to $2.70 \mathrm{eV}$. Thus, the perfluorinated compounds $\mathbf{1 b} \mathbf{- 3} \mathbf{b}$ can act as ambipolar organic semiconductors. 1a-3a and compounds containing pyrrole 4a and $\mathbf{4 b}$ have high LUMOs, and accordingly they can only be suitable for p-type organic semiconducting materials.

\subsection{Charge transport properties of compounds}

3.4.1 Reorganization energy. In order to evaluate the charge transport characteristics for electron and hole of molecules, the reorganization electron energy is first considered. A molecule exhibits a high rate of charge hopping when it has low reorganization energy. The reorganization energy is defined as the sum of geometrical relaxation energies when the species goes from the neutral state geometry to charged state geometry, and vice versa (eqn (6) and (7)):

$$
\begin{aligned}
& \lambda_{\mathrm{h}}=\lambda_{0}+\lambda_{+}=\left[E(\mathrm{M})-E^{0}(\mathrm{M})\right]+\left[E\left(\mathrm{M}^{+}\right)-E^{0}\left(\mathrm{M}^{+}\right)\right] \\
& \lambda_{\mathrm{e}}=\lambda_{0}+\lambda_{-}=\left[E(\mathrm{M})-E^{0}(\mathrm{M})\right]+\left[E\left(\mathrm{M}^{-}\right)-E^{0}\left(\mathrm{M}^{-}\right)\right]
\end{aligned}
$$

where $\lambda_{\mathrm{h}}$ and $\lambda_{\mathrm{e}}$ are reorganization energies for hole and electron, respectively; $E\left(\mathrm{M}^{+}\right)$and $E\left(\mathrm{M}^{-}\right)$the total energies of the cationic and anionic states with the optimized geometries of the neutral ground state, respectively; $E(\mathrm{M})$ the total energy of the neutral state with the optimized geometries of the cationic species (for eqn (6)) and of the anionic species (for eqn (7)); $E^{0}(\mathrm{M}), E^{0}\left(\mathrm{M}^{+}\right)$and $E^{0}\left(\mathrm{M}^{-}\right)$the total energies of the neutral, cationic and anionic ground state species, respectively.

In the present work, the reorganization energies for electron and hole of all compounds are calculated using the B3LYP/6$31 \mathrm{G}(\mathrm{d}, \mathrm{p})$ method and the computed results are listed in Table 3. 
Table 2 Oxidation and reduction potentials and energy levels of HOMO and LUMO of compounds in acetonitrile solution (B3LYP/6$311++G(2 d f, 2 p))$

\begin{tabular}{llllllllllll}
\hline Comp. & $E_{1 / 2}^{\text {red }}$ & $E_{1 / 2}^{\text {oxd }}$ & HOMO & LUMO & Gap & Comp. & $E_{1 / 2}^{\text {red }}$ & $E_{1 / 2}^{\text {oxd }}$ & HOMO & LUMO & Gap (eV) \\
\hline 1a & -2.09 & 1.47 & -6.27 & -2.71 & 3.55 & $\mathbf{1 b}$ & -1.83 & 1.50 & -6.30 & -2.97 & 3.34 \\
2a & -2.20 & 1.12 & -5.92 & -2.60 & 3.32 & $\mathbf{2 b}$ & -1.82 & 1.44 & -6.24 & -2.98 & 3.26 \\
3a & -2.11 & 0.87 & -5.67 & -2.69 & 2.98 & $\mathbf{3 b}$ & -1.82 & 1.25 & -6.05 & -2.98 & 3.07 \\
4a & -2.58 & 0.47 & -5.27 & -2.22 & 3.05 & $\mathbf{4 b}$ & -2.32 & 0.90 & -5.70 & -2.48 & 3.22 \\
\end{tabular}

Except for the relatively large $\lambda_{\mathrm{h}}$ value of $3 \mathrm{a}\left(\lambda_{\mathrm{h}}=0.35 \mathrm{eV}\right.$, Table 3) which is due to a large distortion of its cationic state, the reorganization energies for hole and for electron of 1a-4a are quite low and vary in a range of $0.17-0.19 \mathrm{eV}$ and $0.19-0.28$ $\mathrm{eV}$, respectively. As compared to the computed values of $\mathrm{C}_{16}(\mathrm{PF})_{8}\left(\lambda_{\mathrm{h}}=0.30 \mathrm{eV}\right.$ and $\left.\lambda_{\mathrm{e}}=0.22 \mathrm{eV}\right)$ and perfluoropentacene (PF-PEN) $\left(\lambda_{\mathrm{h}}=0.23 \mathrm{eV}\right.$ and $\left.\lambda_{\mathrm{e}}=0.23 \mathrm{eV}\right)$ which is a typical n-type organic semiconductor, the reorganization energy for hole $\left(\lambda_{h}\right)$ of 1a-4a are properly lower. Their $\lambda_{\mathrm{e}}$ values are close to those of PF-PEN and $\mathrm{C}_{16}(\mathrm{PF})_{8}$. Although the perfluorinated compounds 1b-4b showed the $\lambda_{\mathrm{h}}$ and $\lambda_{\mathrm{e}}$ values a bit higher than those of $\mathbf{1 a - 4 a}$, they are also comparable to those of compounds previously reported.

3.4.2 Dimer interactions and rate of charge hopping $(K)$. To further probe the behaviour of charge transport, we perform calculations of the dimer interactions of molecules considered. The geometries of dimers are constructed in a translational parallel motif (Fig. 4) and optimized by using the B3LYP-3D functional that contains dispersion energy (as denoted by- $D$ ) in conjugation with $6-31 \mathrm{G}(\mathrm{d}, \mathrm{p})$ basis set.

The intermolecular interaction energy of dimers is defined by expression (8):

$$
E_{\text {int }}=2 E_{\text {monomer }}-E_{\text {dimer }}
$$

where $E_{\text {monomer }}$ and $E_{\text {dimer }}$ are total energies of monomer and dimer, respectively. They are computed using the functionals B3LYP-3D and M06. These approaches were previously tested as effective for evaluating the dimer interactions. ${ }^{\mathbf{1 2 , 4 5}}$ To further consider the effect of basis sets used, we performed single point energy calculations on these optimized configurations by using functional M06 in conjuration with three different basis sets, including 6-31G(d,p), 6-311G(d,p) and $6-311+G(d, p)$. Our computed results pointed out that the intermolecular interaction energies of dimers tend to be increased as size of basis sets increased (Table S2, ESI $\dagger$ ). Adding polarized function only somewhat changes the interaction energies of dimers.

Our calculated results are given in Table 3 and compared with calculated properties of the previously reported $\mathrm{C}_{16} \mathrm{~S}_{8}$. We should note that the molecular structures of the designed compounds $\mathbf{1 a - 4 a}$ and $\mathbf{1 b}-\mathbf{4 b}$ are in fact similar to that of sulflower $\mathrm{C}_{16} \mathrm{~S}_{8}$. Thus, a comparison between $\mathrm{C}_{16} \mathrm{~S}_{8}$ and the molecules designed in this work appears useful to understand their charge transport characteristics.

The strong interactions between monomers in dimers of all compounds were observed. The distances between monomers $\left(D_{\text {dimer }}\right)$ vary in a small range of $3.62 \div 3.95 \AA$ and are close to the value of $3.87 \AA$ of $\mathrm{C}_{16} \mathrm{~S}_{8}$ in the same interaction motif. The interaction energies between two monomers amount to $1.04-1.57 \mathrm{eV}$ that is properly larger than the value of $0.98 \mathrm{eV}$ of $\mathrm{C}_{16} \mathrm{~S}_{8}$. Consequently, it can be seen that integral transfers for hole of compounds are comparable to that of $\mathrm{C}_{16} \mathrm{~S}_{8}$, whereas their integral transfers of electron becomes much larger. Since the $\mathrm{C}_{16} \mathrm{~S}_{8}$ was reported as good p-type organic semiconductor, the compounds considered in this work are expected to be appropriate for both n-type and p-type semiconductors.

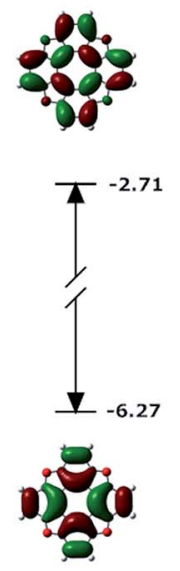

$1 \mathrm{a}$
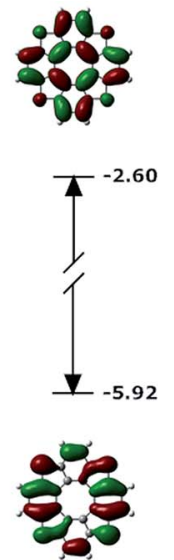

$2 a$
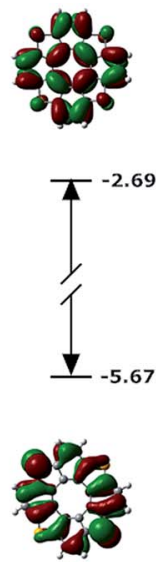

$3 a$
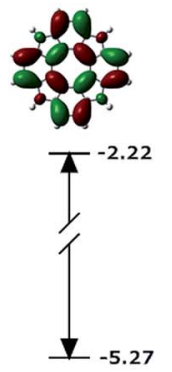

$1 \mathbf{b}$

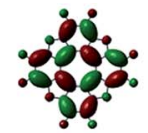

$4 a$

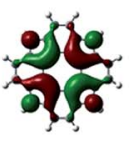

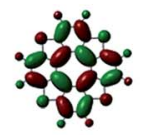
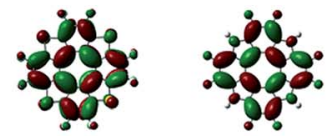

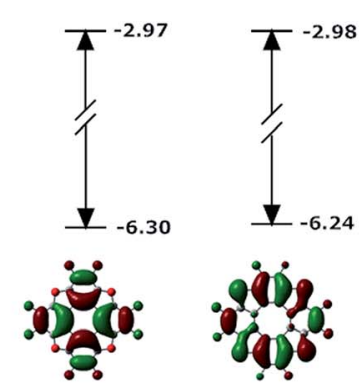

2b
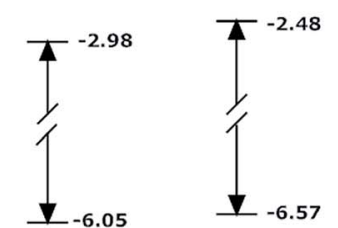
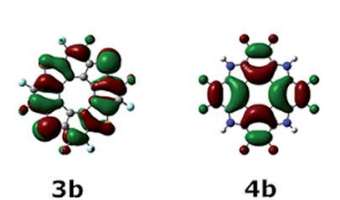

$4 \mathbf{b}$

Fig. 3 Shapes of HOMOs and LUMOs of molecules and their energy levels in unit of eV. 
Table 3 Dimer distances (Å), interaction energies (eV), integral transfer (meV) and rate of charge hopping $\left(\mathrm{s}^{-1}\right)$ of all compounds $1 a-4 a$ and $1 b-$ $4 \mathrm{~b}$

\begin{tabular}{|c|c|c|c|c|c|c|c|c|c|}
\hline \multirow[b]{2}{*}{ Comp. } & \multirow[b]{2}{*}{$D_{\text {dimer }}(\AA)$} & \multicolumn{2}{|c|}{$\begin{array}{l}\text { Interaction energy } \\
(\mathrm{eV})\end{array}$} & \multicolumn{2}{|c|}{$\begin{array}{l}\text { Reorganization } \\
\text { energy }(\mathrm{eV})\end{array}$} & \multicolumn{2}{|c|}{$\begin{array}{l}\text { Integral transfer } \\
(t, \mathrm{meV})\end{array}$} & \multicolumn{2}{|c|}{$\begin{array}{l}\text { Rate of charge hopping } \\
\left(K, \mathrm{~s}^{-1}\right)\end{array}$} \\
\hline & & B3LYP-3D & M06 & Hole & Electron & Hole & Electron & Hole & Electron \\
\hline $1 \mathrm{a}$ & 3.74 & 1.00 & 1.12 & 0.19 & 0.19 & 36 & 27 & $7.88 \times 10^{12}$ & $4.50 \times 10^{12}$ \\
\hline $2 a$ & 3.85 & 1.30 & 1.40 & 0.13 & 0.24 & 7 & 12 & $5.77 \times 10^{11}$ & $5.27 \times 10^{11}$ \\
\hline $3 a$ & 3.95 & 1.30 & 1.34 & 0.35 & 0.28 & 22 & 61 & $4.64 \times 10^{11}$ & $7.47 \times 10^{12}$ \\
\hline $2 b$ & 3.62 & 1.51 & 1.68 & 0.17 & 0.28 & 28 & 16 & $5.73 \times 10^{12}$ & $5.79 \times 10^{11}$ \\
\hline $3 \mathbf{b}$ & 3.68 & 1.57 & 1.60 & 0.24 & 0.34 & 49 & 17 & $7.80 \times 10^{12}$ & $2.93 \times 10^{11}$ \\
\hline $4 \mathrm{~b}$ & 3.80 & 1.36 & 1.51 & 0.25 & 0.29 & 7 & 25 & $1.36 \times 10^{11}$ & $1.21 \times 10^{12}$ \\
\hline $\mathbf{C}_{16} \mathbf{S}_{\mathbf{8}}{ }^{a}$ & 3.87 & - & 0.98 & & & 29 & 6 & & \\
\hline
\end{tabular}

${ }^{a}$ These values obtained from ref. 10 .

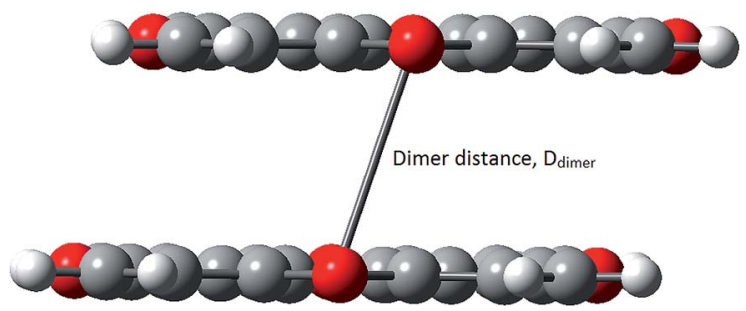

Fig. 4 The translational parallel motif of dimers.

\section{Conclusions}

We theoretically designed a series of new tetra-hetero[8]circulenes based on an inner eight-membered ring. The electronic structure and characteristics of charge transport of all compounds were investigated using DFT based computational methods. Except for the compounds containing Se-atoms (3a and $\mathbf{3 b}$ ), all remaining compounds exhibit planar and highly symmetrical structures with a novel aromatic feature: while the inner eight-membered ring is anti-aromatic, the outer fused rings are aromatic.

The predicted UV spectrum and reduction potential of 1a agree well with available experimental values. Following replacement of $\mathrm{H}$-atoms by F-atoms, the energy levels of frontier orbitals of $\mathbf{1 b}-\mathbf{4} \mathbf{b}$ are consistently decreased as compared to those of 1a-4a.

Based on the properties of electrochemistry and charge transport calculated, the molecules $\mathbf{1 a - 4 a}$ and $\mathbf{4 b}$ can be regarded as good candidates for p-type semiconductors. More importantly, the molecules $\mathbf{1 b} \mathbf{- 3} \mathbf{b}$ are revealed to exhibit characteristics suitable for ambipolar organic semiconductors. Since the n-type and ambipolar organic semiconducting materials remain rare, we would hope that the present results will attract much attention from the experimental scientists.

At the time of finalizing this report, we interestingly found that tetrathio and tetraselono[8]circulenes were experimentally synthesized by Wong et al. ${ }^{65}$

\section{Acknowledgements}

We are indebted to the KU Leuven Research Council (GOA) and Vlaams Supercomputer Centrum (VSC). VTTH and TBT would like to thank the FWO-Vlaanderen for Ph. D. and postdoctoral fellowships.

\section{Notes and references}

1 W. E. Barth and R. E. Lawton, J. Am. Chem. Soc., 1966, 88, 380-381.

2 R. Scholl and K. Meyer, Ber. Dtsch. Chem. Ges. A, 1932, 65, 902-915.

3 K. Yamamoto, T. Harada, M. Nakazaki, Y. Naka, Y. Kai, S. Harada and N. Kasai, J. Am. Chem. Soc., 1983, 105, 71717172.

4 R. Salcedoa, L. E. Sansoresa, A. Picazoa and L. Sansón, J. Mol. Struct.: THEOCHEM, 2004, 678, 211-215.

5 C. N. Feng, M. Y. Kuo and Y. T. Wu, Angew. Chem., Int. Ed., 2013, 52, 7791-7794.

6 K. Y. Chernichenko, V. V. Sumerin, R. V. Shpanchenko, E. S. Balenkova and G. Nenajdenko, Angew. Chem., Int. Ed., 2006, 45, 7367.

7 A. Dadvand, F. Cicoira, Y. K. Chernichenko, E. S. Balenkova, R. M. Osuna, F. Rosei, V. G. Nenajdenko and D. F. Perepichka, Chem. Commun., 2008, 5354-5356.

8 A. Datta and S. K. Pati, J. Phys. Chem. C, 2007, 19, 4487-4490. 9 S. Mohakud and S. K. Pati, J. Mater. Chem., 2009, 19, 43564361.

10 G. Gahungu, J. Zhang and T. Barancira, J. Phys. Chem. A, 2009, 113, 255-262.

11 X. D. Tang, Y. Liao, H. Z. Gao, Y. Geng and Z. M. Su, J. Mater. Chem., 2012, 22, 6907-6918.

12 V. T. T. Huong, T. B. Tai and M. T. Nguyen, Phys. Chem. Chem. Phys., 2012, 14, 14832-14841.

13 T. K. Mandal, D. Jose, A. Nijmudheen and A. Datta, J. Phys. Chem. C, 2014, 118, 12115-12120.

14 T. B. Tai, V. T. T. Huong and M. T. Nguyen, Chem. Commun., 2013, 49, 11548-11550. 
15 H. Erdtman and H. E. Högberg, Chem. Commun., 1968, 773774.

16 (a) B. F. Minaev, G. V. Baryshnikov and V. A. Minaeva, Comput. Theor. Chem., 2011, 972, 68-74; (b) V. A. Minaeva, B. F. Minaev, G. V. Baryshnikov, H. Agren and M. Pittelknow, Vib. Spectrosc., 2012, 61, 156-166; (c) N. N. Karaush, B. F. Minaev, G. V. Baryshnikov and V. A. Minaeva, Opt. Spectrosc., 2014, 116, 37-51; (d) V. A. Minaeva, B. F. Minaev, G. V. Baryshnikov, O. A. Romeyko and M. Pittelknow, Vib. Spectrosc., 2013, 65, 147-158; (e) G. V. Baryshnikov, B. F. Minaev, V. A. Minaeva, A. T. Baryshnikova and M. Pittelknow, $J$. Mol. Struct., 2012, 1026, 127-132.

17 (a) G. V. Baryshnikov, R. R. Valiev, N. N. Karaush and B. F. Minaev, Phys. Chem. Chem. Phys., 2014, 16, 1536715374; (b) G. V. Baryshnikov, B. F. Minaev, V. A. Minaeva and V. G. Nenajdenko, J. Mol. Model., 2013, 19, 4511-4519.

18 C. B. Nielsen, T. Brock-Nannestad, T. K. Reenberg, P. Hammershøj, J. B. Christensen, J. W. Stouwdam and M. Pittelkow, Chem.-Eur. J., 2010, 16, 13030-13034.

19 (a) C. B. Nielsen, T. Brock-Nannestad, P. Hammershoj, T. K. Reenberg, M. S. Magnussen, D. Trpcevski, T. Hessel, R. Salcado, G. V. Baryshnikov, B. F. Minaev and M. Pittelkow, Chem.-Eur. J., 2013, 19, 3898-3904; (b) T. Hensel, D. Trpcevski, C. Lind, R. Grosjean, P. Hammershoj, C. B. Nielsen, M. S. Magnussen, B. Minaev, G. V. Baryshnikov and M. Pittelkow, Chem.-Eur. J., 2013, 19, 17097-17102; (c) V. A. Minaeva, B. F. Minaev, G. V. Baryshnikov and M. Pittelkow, Opt. Spectrosc., 2013, 114, 509-512.

20 G. V. Baryshnikov, B. F. Minaev, N. N. Karaush and V. A. Minaeva, Phys. Chem. Chem. Phys., 2014, 16, 6555-6559.

21 G. V. Baryshnikov, B. F. Minaev, N. N. Karaush and V. Minaeva, RSC Adv., 2014, 4, 25843-25851.

22 C. Lee, W. Yang and R. G. Parr, Phys. Rev. B: Condens. Matter Mater. Phys., 1988, 37, 785-789.

23 A. D. Becke, Phys. Rev. A: At., Mol., Opt. Phys., 1988, 38, 30983100 .

24 P. J. Stephens, F. J. Devlin, C. F. Chabalowski and M. J. Frisch, J. Phys. Chem., 1994, 98, 11623-11627.

25 P. C. Harihara and J. A. Pople, Theor. Chim. Acta, 1973, 28, 213-222.

26 M. M. Francl, W. J. Petro, W. J. Hehre, J. S. Binkley, M. S. Gordon, D. J. DeFrees and J. A. Pople, J. Chem. Phys., 1982, 77, 3654-3665.

27 G. W. Trucks, et al., Gaussian 09, Revision A.02, Gaussian, Inc., Wallingford, CT, 2009.

28 S. F. Nelsen and F. Blomgren, J. Org. Chem., 2001, 66, 65516559.

29 S. F. Nelsen, D. A. Trieberi, R. F. Ismagilov and Y. Teki, J. Am. Chem. Soc., 2001, 123, 5684-5694.

30 M. Malagoli and J. L. Brédas, Chem. Phys. Lett., 2000, 327, 1317.

31 K. Sakanoue, M. Motoda, M. Sugimoto and S. Sakaki, J. Phys. Chem. A, 1999, 103, 5551-5556.

32 X. Y. Li, J. Tong and F. C. He, Chem. Phys., 2000, 260, 283294.
33 R. A. Marcus and N. Sutin, Biochim. Biophys. Acta, 1985, 811, 265-322.

34 R. A. Marcus, Rev. Mod. Phys., 1993, 65, 599-610.

35 A. Troisi and G. Orlandi, Chem. Phys. Lett., 2001, 344, 509518.

36 A. Troisi and G. Orlandi, J. Phys. Chem. A, 2006, 110, 40654070.

37 S. Yin, Y. Yi, Q. Li, G. Yu, Y. Liu and Z. Shuai, J. Phys. Chem. A, 2006, 110, 7138-7143.

38 J. P. Perdew, J. A. Chevary, S. H. Vosko, K. A. Jackson, M. R. Pederson, D. J. Singh and C. Fiolhais, Phys. Rev. B: Condens. Matter Mater. Phys., 1992, 46, 6671-6687.

39 J. P. Perdew, K. Burke and Y. Wang, Phys. Rev. B: Condens. Matter Mater. Phys., 1996, 54, 16533-16539.

40 J. Huang and M. Kertesz, Chem. Phys. Lett., 2004, 390, 110115.

41 H. Li, R. Zheng and Q. Shi, J. Phys. Chem. C, 2012, 116, 11886-11894.

42 X. Yang, L. Wang, C. Wang, W. Long and Z. Shuai, Chem. Mater., 2008, 20, 3205-3211.

43 G. Nan and Z. Li, Org. Electron., 2012, 13, 1229-1236.

44 X. Yang, Q. Li and Z. Shuai, Nanotechnology, 2007, 18, 424029.

45 V. T. T. Huong, T. B. Tai and M. T. Nguyen, Phys. Chem. Chem. Phys., 2012, 14, 14832-14841.

46 X. D. Tang, Y. Liao, H. Z. Gao, Y. Geng and Z. M. Su, J. Mater. Chem., 2012, 22, 6907-6918.

47 X. K. Chen, L. Y. Zou, J. F. Gou and A. M. Ren, J. Mater. Chem., 2012, 22, 6471-6484.

48 (a) J. Huang and M. Kertesz, Chem. Phys. Lett., 2004, 390, 110-115; (b) C. Sutton, J. S. Sears, V. Coropceanu and J.-L. Bredas, J. Phys. Chem. Lett., 2013, 4, 919.

49 A. P. Davis and A. J. Fry, J. Phys. Chem. A, 2010, 114, 1229912304.

50 A. V. Marenich, C. J. Cramer and D. G. Truhlar, J. Phys. Chem. B, 2009, 113, 6378-6396.

51 M. Namazian, C. Y. Lin and M. L. Coote, J. Chem. Theory Comput., 2010, 6, 2721-2725.

52 J. E. Bartmess, J. Phys. Chem., 1994, 98, 6420-6424.

53 G. Nan, X. Yang, L. Wang, Z. Shuai and Y. Zhao, Phys. Rev. B: Condens. Matter Mater. Phys., 2009, 79, 115203.

54 S. Chai, S. H. Wen, J. D. Huang and K. L. Han, J. Comput. Chem., 2011, 32, 3218-3225.

55 (a) G. Gahungu, B. Zhang and J. P. Zhang, J. Phys. Chem. C, 2007, 111, 4838-4846; (b) G. Gahungu and J. Zhang, Phys. Chem. Chem. Phys., 2008, 10, 1743-1747.

56 C. Wartelle, R. Viruela, P. M. Viruela, F. X. Sauvage, M. Salle, E. Orti, E. Levillain and F. Le Derf, Phys. Chem. Chem. Phys., 2003, 5, 4672-4679.

57 E. G. Kim, V. Coropceanu, N. E. Gruhn, R. S. SanchezCarrera, R. Snoeberger, A. J. Matzger and J. L. Bredas, J. Am. Chem. Soc., 2007, 129, 13072-13081.

58 S. T. Bromley, M. Mas-Torrent, P. Hadley and C. Rovira, J. Am. Chem. Soc., 2004, 126, 6544-6545.

59 P. v. R. Schleyer, H. Jiao, N. J. R. V. E. Hommes, V. G. Malkin and O. L. Malkina, J. Am. Chem. Soc., 1997, 119, 1266912670. 
60 T. B. Tai, N. M. Tam and M. T. Nguyen, Theor. Chem. Acc., 2012, 131, 1241 and references therein.

61 J. Andzelm, B. C. Rinderspacher, A. Rawlett, J. Dougherty, R. Baer and N. Govind, J. Chem. Theory Comput., 2009, 5, 2835-2846.

62 D. Jacquemin, V. Wathelet, E. A. J. Perpete and C. Adamo, J. Chem. Theory Comput., 2009, 5, 2420-2435.
63 C. R. Newman, C. D. Frisbie, D. A. S. Filho, J. L. Bredas, P. C. Ewbank and K. P. Mann, Chem. Mater., 2004, 16, 4436-4451 and references therein.

64 A. V. Marenich, C. J. Cramer and D. G. Truhlar, J. Phys. Chem. B, 2009, 113, 6378-6396.

65 X. Xiong, C. L. Deng, B. F. Minaev, G. V. Baryshnikov, Z. S. Peng and H. N. C. Wong, Chem.-Asian J., 2015, DOI: 10.1002/asia.201403028. 